\title{
Integrating Social Knowledge and Collaboration Tools into Dispersed Product Development
}

\author{
http://dx.doi.org/10.3991/ijac.v8i2.4548 \\ R.D. Evans ${ }^{1}$, J.X. Gao ${ }^{1}$, N. Martin ${ }^{2}$ and C. Simmonds ${ }^{2}$ \\ ${ }^{1}$ University of Greenwich, United Kingdom \\ 2 Electronic Systems, BAE Systems, Rochester, United Kingdom
}

\begin{abstract}
Employee collaboration and knowledge sharing is vital for manufacturing organisations wishing to be successful in an ever-changing global market place; Product Development (PD) teams, in particular, rely heavily on these activities to generate innovative designs and enhancements to existing product ranges. To this end, the purpose of this paper is to present the results of a validation study carried out during an Engineering Education Scheme project to confirm the benefits of using bespoke Web 2.0-based groupware to improve employee collaboration and knowledge sharing between dispersed PD teams. The results of a cross-sectional survey concluded that employees would welcome greater usage of social computing technologies. The study confirmed that groupware offers the potential to deliver a more effective collaborative and knowledge sharing environment with additional communication channels on offer. Furthermore, a series of recommended guidelines are presented to show how PD teams, operating in globallydispersed organisations, may use Web 2.0 tools to improve employee collaboration and knowledge sharing.
\end{abstract}

Index Terms-Aerospace and Defence Manufacturing, Employee Collaboration, Engineering Education, Knowledge Management, Product Development, Web 2.0.

\section{INTRODUCTION}

The last two decades have been characterised by technological advancement highlighted by the birth of the World Wide Web (WWW) and the development of social computing technologies, such as social networking sites, social bookmarking and micro-blogging tools; this has resulted in many opportunities for manufacturing organisations operating globally, but also significant challenges, especially in terms of employee and project collaboration, with companies today needing to enhance communication channels between geographically-dispersed and co-located employees and external partners.

The Aerospace and Defence Industry (ADI) is an industrial sector which plays a key role in global manufacturing and where the UK enjoys a continuing reputation as a world leader [1]. The industry is renowned for its product innovation and the aerospace industry, in particular, may be considered an example of engineering excellence. Revenue generated by the aerospace industry alone is increasing at an annualized rate of 5\% with a new record being set in 2014 for production output, mainly due to the replacement of obsolete aircrafts by next-generation, more fuel-efficient machines together with the ongoing increase in air travel, particularly in the Middle East and Asia Pacific regions [2].
The ADI is typified as employing highly skilled and competent workforces, which allow companies to compete effectively worldwide [3]. In the UK, for example, there are currently over 2600 companies operating in the sector [4] and within Europe the sector accounts for over $1.9 \%$ of total employment [5]; the majority of these employees are often co-located or geographically dispersed around their home countries, but typically conduct business and collaborate with colleagues based overseas as they are often part of large multi-national organisations.

Engineering practices and standards within the ADI are typically based upon high quality components, highly technical data and extended development and production lead times [6]. The development of innovative products has now extended its scope to incorporate a wider range of activities and, in addition to greater functional breadth, has to accommodate the geographical dispersement of both internal and external colleagues. To this end, social computing provides opportunities to enhance employee collaboration and knowledge sharing and, thereby, release creativity and create an organisational culture of innovation and ideation. Since 2006, when McAfee [7] introduced the term Enterprise 2.0 to identify the emerging use of Web 2.0-based technologies in business, dramatic growth in their adoption has been evident, however, work still remains to create bespoke, customised solutions to meet specific business processes, including the product development lifecycle, but which still fit within the usability parameters of McAfee's SLATES model so that organisations may make best use of web 2.0 tools within the enterprise, as shown in Figure 1.

By employing Web 2.0 in business, organisations are able to connect people to people and people to information more effectively; facilitate connectivity, sharing and collaboration across boundaries; capture a wide base of views and information that is usually informal or highly dispersed throughout the organisation; help colleagues locate

\begin{tabular}{llc} 
S earch & $\longrightarrow$ & $\begin{array}{c}\text { "Discoverability of } \\
\text { Information and Knowledge" }\end{array}$ \\
\hline L inks & $\longrightarrow$ & "Build and share links to content" \\
\hline A uthoring & $\longrightarrow \begin{array}{c}\text { "Generate content - contribute own } \\
\text { knowledge, ideas and experiences" }\end{array}$ \\
\hline T ags & $\longrightarrow \begin{array}{c}\text { "Upload and annotate content with } \\
\text { own keywords and share" }\end{array}$ \\
\hline Extensions & $\longrightarrow \begin{array}{c}\text { "Intelligent Knowledge Based } \\
\text { Systems match preferences to users" }\end{array}$ \\
\hline S ignals & $\longrightarrow \begin{array}{c}\text { "Make others aware when new } \\
\text { content is uploaded" }\end{array}$
\end{tabular}

Figure 1. Adaptation of McAfee's Enterprise 2.0 SLATES Model 
previously unknown experts; and discover hidden organisational knowledge [8]. Published academic research into the use of Web 2.0 technologies in business has focused primarily on the use of individual technologies, such as Blogs [9], Wikis [10], Social Bookmarking [11], Micro-Blogging [12] and Social Networking [13]. However, there is limited research into the adoption and usage of a combination of these tools in the form of groupware, especially within an ADI Product Development (PD) environment.

The purpose of this paper is to report on an investigative validation study conducted following the development and deployment of a bespoke Web 2.0-based groupware, which is introduced in section $\mathrm{V}$, within a leading ADI organisation, BAE Systems' Electronic Systems, Rochester, and Tonbridge School, a secondary school based in Kent, UK. The study aimed to validate, through a real-world New Product Development (NPD) project, the benefits on offer to companies when adopting Web 2.0 tools within dispersed PD teams. Furthermore, instructional guidelines are provided on how to integrate Web 2.0 tools into the product development process; these have been formulated following observational studies of PD design engineers and discussions with management within the collaborating company.

\section{Challenges Facing The NPD PROCESS}

The design and development of both existing and new products traditionally embraces corporate strategy, market research and analysis, the development and testing of prototypes and production planning [14]. Nowadays, however, NPD has extended its scope to incorporate a wider range of corporate activities and, in addition to greater functional breadth, it now has to accommodate the geographical dispersement of both internal and external colleagues, encourage interaction and multi-disciplinary activity and embrace the concept of managing product lifecycles.

The management of products during their lifecycle progresses through several stages, from product conceptualisation, design and manufacture to service and disposal, as illustrated in Figure 2, and the need for employee collaboration and knowledge sharing during all stages of this process is seen as crucial [15]. The fundamental goals of PD embrace inter alia reductions in cost and product enhancements in order to meet and ideally exceed customer requirements. However, a key challenge facing the PD process is how to facilitate employee and project collaboration more effectively within NPD teams, particularly sharing and developing concepts, ideas and explicit knowledge.

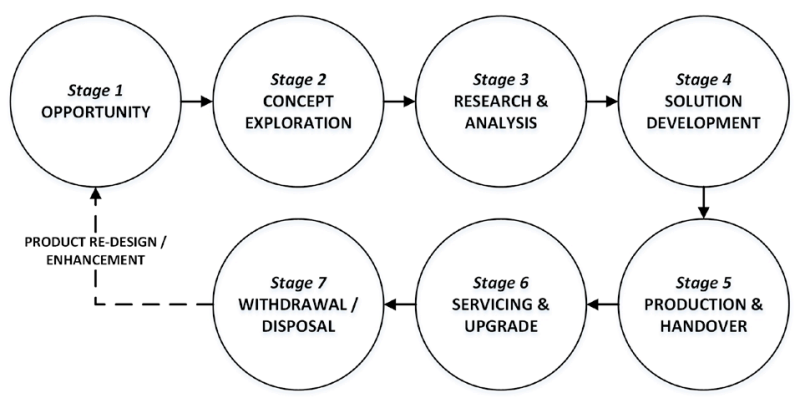

Figure 2. Generic Product Lifecycle
To this end, Web 2.0-based technologies provide the PD process with greater opportunities to enhance collaborative practices and, thereby, release creativity and foster employee innovation. They are capable of underpinning effective PD and lifecycle management, which in turn can be vital in maintaining competitive advantage and the future sustainability and growth of companies [16]. Web 2.0 technologies can also allow organisations to interact more freely with customers and suppliers located around the world, enabling them to react more quickly and more effectively to market changes and meet agile and lean manufacturing goals.

\section{BARRIERS TO CORPORATE EMPLOYEE COLLABORATION}

It is recognised [17] that employee collaboration faces numerous barriers in the workplace, which are often due to social or technological factors. Firstly, employee trust is seen as a potential barrier when an employee is deciding whether it is beneficial to engage in collaboration or not, as often they fear that colleagues may take credit for the work they have previously submitted. There is also potential language or cultural barriers which inhibit employee collaboration in multi-national organisations or between collaborating entities; additionally, inconsistencies often exist in corporate policies in relation to employee collaboration, which can result in colleagues being unaware of the procedures and processes to follow when interacting with different sites or business units within the same organisation.

The activity of Knowledge Management (KM), which is researched extensively in its own right, is a significant factor with regard to employee and project collaboration as employees may not know who possesses, within their extended project teams or organisation, the desired knowledge or skill-sets to help them with given tasks. Additionally, employees often perceive knowledge as power and may not wish to contribute their expertise to facilitate collaboration with colleagues during PD projects. Specifically in the case of extended supply or customer chains, barriers may also be perceived in relation to the sharing of proprietary corporate information as employees may see such information being susceptible to further inadvertent or deliberate external exposure when others are collaborating on projects outside the scope of the project in question.

From a technology point of view, organisations may experience interoperability issues when installing commercial groupware within current IT infrastructures. Lack of employee training and an explanation of the benefits on offer to employees when using new groupware solutions is also identified as a potential barrier to success [18]. From a manufacturing point of view, organisations must ensure that the groupware employed is capable of handling diverse engineering file formats, including Computer Aided Design (CAD) and Product Lifecycle Management (PLM) or other similar file types.

While promoting and adopting the use of Web 2.0based technologies in enterprise practices, organisations must always seek to minimise barriers as Enterprise 2.0 offers the potential for enhanced employee collaboration in a less formal and intuitive manner. 


\section{THE POTENTIAL OFFERED BY ENTERPRISE 2.0 TECHNOLOGIES TO AEROSPACE AND DEFENCE NPD}

Since 2006, when McAfee [7] introduced the term Enterprise 2.0 to clearly identify the emerging use of Web 2.0 technologies in the world of business, we have seen a dramatic growth in the adoption of such tools in a business context. Today, extensive amounts of data and explicit employee knowledge exist in various file formats, including images, videos and engineering files, such as CAD documents and work-instructions for assembly line operators. Web 2.0 technologies are considered more social in nature than traditional corporate IT systems and allow for more dynamic interaction between clients and servers, more engaging webpage displays and, ultimately, more direct and participative user-to-user interactions.

The term 'Groupware' refers to multi-user collaborative working tools, which assist users when collaborating on common projects; they may be used either synchronously, where users collaborate in real-time (e.g. Instant Messaging), or asynchronously, when users collaborate at different times (e.g. leaving messages for co-workers based in different time zones - micro-blogging or private messaging), effectively creating a continuous work cycle. They allow collaboration to take place between both co-located teams, working at the same business site, and dispersed PD teams, often based at diverse locations, possibly around the world.

Groupware systems are typically studied in the interdisciplinary field of Computer Supported Cooperative Work, where research has primarily been conducted into understanding how people work together using these collaborative systems and how they interact with them $[19,20]$. Within industry, groupware solutions, such as Salesforce Chatter, Yammer and Basecamp are predominately offered as one-off packages or as a Software as a Service (SaaS) solution, which may be deployed across various business functions within an organisation or supply chain; these solutions often share common web 2.0 functionality (see Table I), which allows employees within an organisation to better communicate, collaborate and share information and knowledge with dispersed and co-located colleagues.

There has been limited academic research conducted into the use of collaborative groupware within a PD or manufacturing setting, especially when they are considered within an ADI organisation; previously, academics have focused on the use of groupware from a KM standpoint $[21,22]$. For the purpose of this study, the authors designed and developed a bespoke groupware solution to meet specifically the needs of the two dispersed collaborating organisations. In order to establish which web 2.0based functionality was required by both parties, informal face-to-face discussion forums were held, prior to development, to debate and agree on the functionality of the preferred solution; wireframes and visual mock-ups were produced, such as that shown in Figure 3, before a final design (Figure 5) was decided upon by a select panel from both collaborating companies.

\section{ADI ACADEMIC-INDUSTRY CASE STUDY}

BAE Systems plc. is a multinational organisation employing, at the time of writing, approximately 88,200 staff worldwide across its range of businesses. The enterprise is the second largest aerospace, defence and security compa-
TABLE I.

COMMON WEB 2.0 FUNCTIONALITY EMPLOYED

\begin{tabular}{|l|l|}
\hline \multicolumn{1}{|c|}{$\begin{array}{c}\text { Web 2.0 Func- } \\
\text { tionality }\end{array}$} & \multicolumn{1}{c|}{ Definition } \\
\hline Micro-Blogging & $\begin{array}{l}\text { Users have the ability to post short, character } \\
\text { limited messages, to a web feed for others to see. }\end{array}$ \\
\hline Instant Messaging & $\begin{array}{l}\text { A form of web-based text communication between } \\
\text { colleagues and friends at different locations. }\end{array}$ \\
\hline Activity Streams & $\begin{array}{l}\text { A web-based feed which provides users with } \\
\text { regularly updated content. }\end{array}$ \\
\hline Wikis & $\begin{array}{l}\text { A web-based tool which allows users to create, edit } \\
\text { and update personalised web content. }\end{array}$ \\
\hline Discussion Boards & $\begin{array}{l}\text { A website or web page where users are able to } \\
\text { converse in text conversations. }\end{array}$ \\
\hline Event Scheduling & $\begin{array}{l}\text { An online facility to share updates on forthcoming } \\
\text { events together with the ability to invite colleagues } \\
\text { to attend or contribute. }\end{array}$ \\
\hline $\begin{array}{l}\text { Social Bookmark- } \\
\text { ing }\end{array}$ & $\begin{array}{l}\text { The practice of creating a centralised reference list } \\
\text { of web documents which may be accessed and } \\
\text { edited by colleagues. }\end{array}$ \\
\hline
\end{tabular}

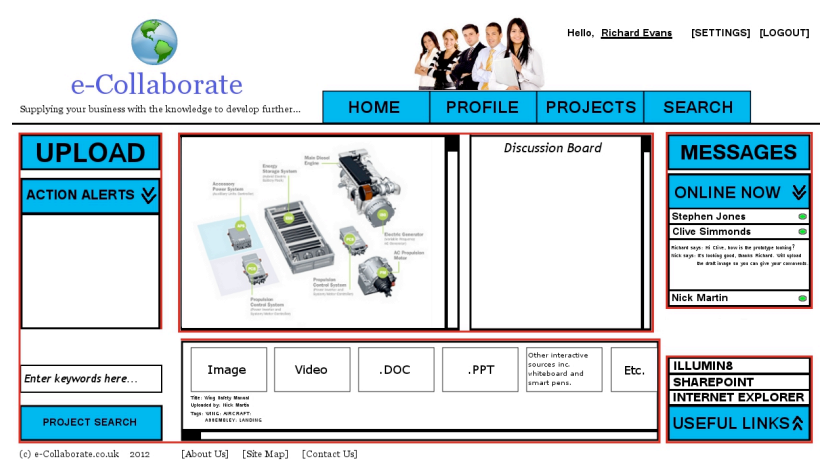

Figure 3. Visual Mock-Up of Developed Groupware

ny in the world and in 2013 reported sales of over $£ 18.2$ billion [23]. An independent bench-marking study commissioned by BAE Systems [24] showed that practices in relation to employee collaboration within the ADI organisation were judged to be "average" when compared to similar types of organisations.

Studies previously carried out by the author of this paper $[25,26]$, concluded that BAE Systems employees demonstrate a high degree of familiarity with current Web 2.0 technologies, but that little use is being made of these tools in an industrial setting, with employees still relying heavily on traditional means of communication, such as email and face-to-face meetings, for PD project collaboration. Based on the findings of the authors previous work, a collaborative groupware was developed and customised using an open-source Drupal solution (Open Atrium) hosted on a remote Linux server at the University of Greenwich; a system diagram is shown in Figure 4 to illustrate how employees of the two collaborating organisations may operate and interact with the groupware to improve employee collaboration and communication.

The groupware developed employed a range of userdefined web 2.0 functionality, including:

- Personalised User Profile Pages, which display contact details for each user, previous work history within the collaborating organisation and relevant knowledge and skills to their job role;

- Project Timeline, which allows for group messaging between colleagues, file sharing and content tagging 
and enables crowdsourcing within project teams to provide users with the functionality to gather feedback on PD ideas and prototypes;

- Who's Online notifications, which alert users when colleagues are available for one-to-one instant messaging;

- Project Quick Chat, which incorporates microblogging functionality allowing users to leave one-tomany messages, which can be read by users when they next log-in to the groupware site;

- Project Planner, which allows for event scheduling, such as daily or weekly project SCRUM meetings;

- Recent Comments, which display contributions from team members in a chronological order;

- Action Alerts, which notify users when new content or information has been added or updated on the groupware site; and an

- Advanced Search Facility which allows users to search for relevant content regarding a project and filter content based on keywords and phrases.

The groupware could be accessed through desktop, laptop or tablet computers based at each collaborating organisation, as well as through mobile devices; Figure 5 shows the user front-end of the groupware solution, which is displayed when a project team member accesses the groupware tool.

An annual Engineering Education Scheme (EES) project has been operated by BAE Systems for over 10 years and presents engineering students with the opportunity to develop functional prototypes directly relevant to business needs. The project, providing the basis of this case study, called for the creation of an automatic dimming system for use with BAE Systems' ULTRA-Vis system. To facilitate this project, the collaborative groupware developed, named e-Collaborate for the purposes of the research, was employed by all project members.

A validation study of the groupware was undertaken to assess the functionality of the developed solution and to verify the contribution made to enhanced employee collaboration and knowledge sharing. This was achieved via deployment of the groupware in a real-world PD scenario during the EES project. The geographically-dispersed project group comprised three technologically-aware students from Tonbridge School, the school's Head of Technology, who acted as Project Manager, and two graduate manufacturing engineers from BAE Systems' Electronic Systems, who acted as mentors. The validation study was completed as an ad-hoc activity and deployment of the groupware extended from $30^{\text {th }}$ January to $20^{\text {th }}$ March 2013.

\section{Methodology: Data COLlection AND ANALYSIS}

The methodology employed was an empirical case study, which adopted a web-based cross-sectional survey investigation, hosted on www.smart-survey.co.uk, and an audio-recorded focus group, which convened post-survey. Surveys were designed to gather feedback from two separate groups, viz. Students ("Team Members") and Project Manager/Mentors ("Managers"). The survey asked Team Members a total of 35 questions and Managers a total of 39 and focused upon the usability of the groupware as

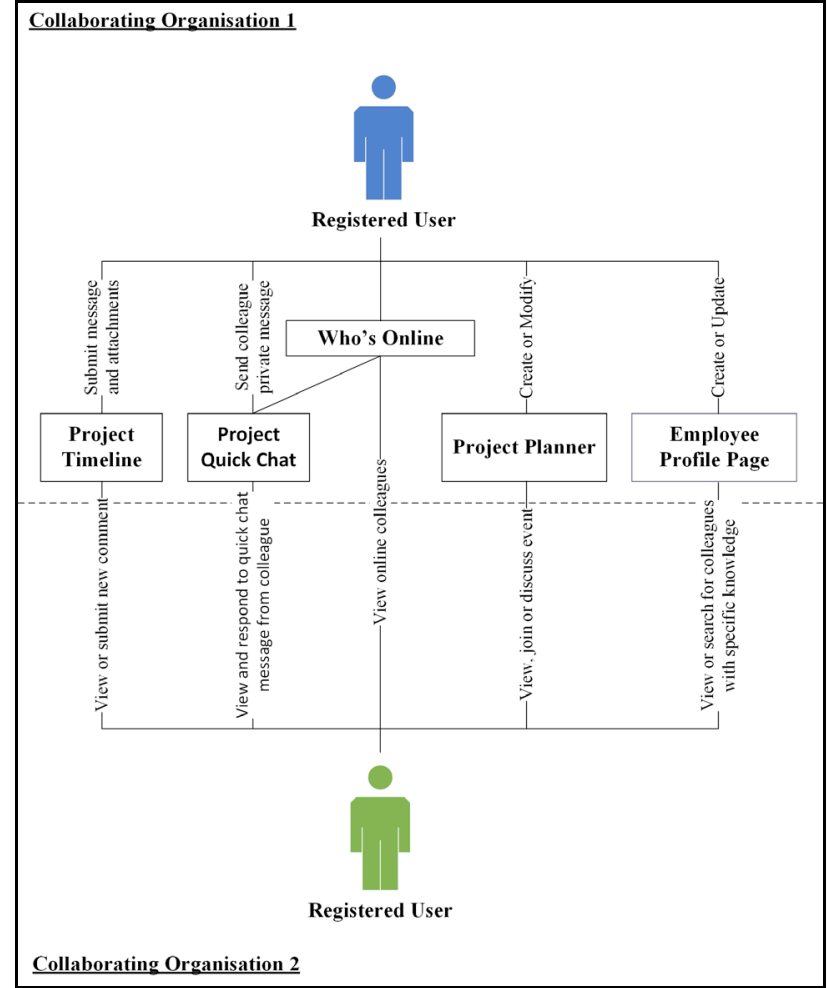

Figure 4. Groupware System Diagram

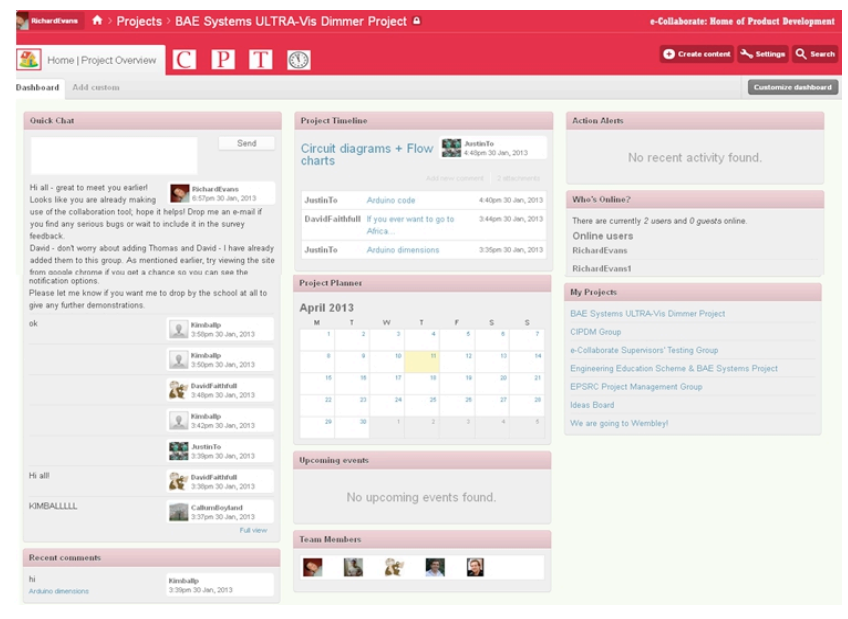

Figure 5. Groupware User Front-End

both a collaboration and management tool. Feedback was gathered from six users: three Team Members and three Managers. The age profile of the participants ranged from late teens to $60+$. In terms of familiarity with current web 2.0-based solutions, all were either moderately or extremely familiar with Facebook and Youtube, but other sites, such as Twitter or Flickr, were less well known to the user group; all users considered themselves moderately or very competent in using these types of usercontributed sites.

\section{RESULTS}

The interpretation of the results derived from the survey has been based on a five-point Likert scale as displayed in Table II, while feedback from both Managers and Team Members has been consolidated for analysis purposes, unless any significant divergence of views was noted. 
TABLE II.

LIKERT SCALE EMPLOYED DURING INVESTIGATION

\begin{tabular}{|c|c|c|c|c|}
\hline $\mathbf{1}$ & $\mathbf{2}$ & $\mathbf{3}$ & $\mathbf{4}$ & $\mathbf{5}$ \\
\hline Not at All & Slightly & Somewhat & Very & Extremely \\
\hline
\end{tabular}

Findings indicated that employees would welcome greater adoption of Web 2.0-based technologies and a range of potential applications were identified; these included better problem solving, improved sharing of ideas, enhanced project collaboration and more effective employee communication.

With regard to the specific functionality on offer via the developed groupware, diverse views were expressed.

- Slightly to Very Useful: Project Timeline, Quick Chat, Recent Comments and Personalised User Profiles were all considered to be useful with scores ranging from 2-4 on the Likert scale;

- Slightly to Somewhat Useful: Action Alerts and Project Planner were perceived less positively and scored 2-3;

- Slightly or Not at All Impersonal: This positive view was expressed by Managers, although Team Members were somewhat less positive. Interestingly, one Team Member suggested that "it is harder to tell what people are thinking if you can't see their face"; and

- Somewhat Slower: Managers and Team Members all expressed this opinion when asked to compare the groupware against traditional methods of communication. It was highlighted that more than one Team Member needed to be online concurrently to ensure satisfactory and speedy employee collaboration.

In relation to a series of open-ended questions regarding the advantages and disadvantages of using the developed groupware, the Managers and Team Members provided differing perspectives. These are now summarised.

\section{A. Managers' View}

One Manager identified specific advantages of using the groupware for supervisory purposes - namely, the fact that individuals do not need to be face-to-face; he stated that the groupware "could be very advantageous when project team members are some distance from each other"; indeed, all three Managers recognised the benefits of the groupware for work within dispersed PD teams. When asked whether they would recommend the groupware for project collaboration and knowledge sharing, the Managers recognised the potential on offer, but suggested that more traditional methods of communication, such as emails, telephone and face-to-face talking, were more direct and, therefore, potentially quicker; they felt that the developed groupware would have to be specified as the preferred collaboration and knowledge sharing tool in order to encourage widespread adoption. Making a general comment, one Manager in particular liked the concept as "it tries to give a one-stop-shop for all information and knowledge", although he did state that "some functionality needs to be added to bring it in line with current expected standards". Finally, in terms of disadvantages of the groupware, it was reported that there is potential for a lack of personal attention being paid to individuals ... with another layer "between people, things could get done slower". Furthermore, while Quick Chat, the embedded micro-blogging facility, was generally seen to work effec- tively, it was noted that team members ideally need to be logged in concurrently to optimise effective collaboration.

\section{B. Team Members' View}

In the case of Team Members, one was particularly positive when using the groupware and identified several advantages: "you can see what people have previously written"; "you can upload pictures, website links and videos for others to view"; "meetings do not need to be planned and you can upload content for people to see at any time". Indeed, it was noted that the groupware was similar in functionality to more established document sharing platforms. A second Team Member opined that "if you use it from the beginning, it would be easy to communicate with everyone relatively quickly, but you have to use it as your only means of contact, other than face to face"... otherwise, people will revert to e-mail. A third Team Member was most positive stating "I feel it is very productive and useful as it combines many aspects of a project onto one website".

There was little evidence of improved collaborative and knowledge sharing outcomes being generated through the use of the groupware during this time-limited validation study, but one Team Member did state that it "offered another means of communication and a good way to share files with colleagues and the rest of the group"; the view was also expressed that "we were under time pressure and I believe that using the groupware allowed us to organise ourselves more and get more done"; in future, an exploratory study which embeds the groupware into a PD environment from the start of a product's lifecycle until the end is planned.

\section{PROPOSED RECOMMENDED GUIDELINES}

The guidelines, shown in Table III, have been produced following an extensive analysis of the opinions and views of 67 senior members of staff within the collaborating company; this allowed the author to gain a comprehensive understanding of the typical tasks and communication methods that engineers employ when working on PD projects. The results of this comprehensive study conducted by the authors can be found in the following publications: [25, 26, 27].

Through analysis, the authors studied the characteristics of the more popular Web 2.0 technologies available today and considered their relationship to the common tasks undertaken during the PD process; this allowed the characteristics and functionality of each technology to be correlated with the PD tasks in order to formulate the proposed guidelines. Finally, after further evaluation with management to confirm which technologies were relevant to the needs of the organisation, the guidelines were formulated and are presented in Table III.

Given the nature of contemporary ICT technologies, which are continually evolving and being developed, it is not claimed that the guidelines are exhaustive. However, it is believed that they provide an informed overview of the more common Web 2.0 technologies which may be employed to best effect to enhance collaborative and knowledge sharing practices within organisations seeking to optimise their PD activities. By adopting the foregoing suggestions, organisations may improve the flow of information and knowledge during their PD processes and, consequently, create more value added designs and product/servicing offerings to satisfy commercial demands, ultimately resulting in potential competitive advantage. 
TABLE III.

PROPOSED RECOMMENDED GUIDELINES

\begin{tabular}{|c|c|}
\hline Technology & Use to... \\
\hline Blogs & $\begin{array}{l}\text { - Inform colleagues and teams of current actions and future objectives; } \\
\text { - Summarise status of projects following review meetings; } \\
\text { - Disseminate information, knowledge and expertise; } \\
\text { - Evaluate and review product ideas and designs; } \\
\text { - Share results, opinions and views within teams; } \\
\text { - Maintain informal contact with external partners; } \\
\text { - Obtain customer feedback relating to product designs and ideas; and } \\
\text { - Encourage team feedback and comments. }\end{array}$ \\
\hline Wikis & $\begin{array}{l}\text { - Create, organise and collaborate on PD documents, including guides and instructions; } \\
\text { - Manage version control; } \\
\text { - Brainstorm ideas within one document; } \\
\text { - Provide up to date work instructions for assembly teams; } \\
\text { - Record project updates, which are accessible by all team members; and } \\
\text { - Collect and store information and knowledge from employees. }\end{array}$ \\
\hline Forums & $\begin{array}{l}\text { - Brainstorm ideas; } \\
\text { - Facilitate discussions outside formal settings; } \\
\text { - Submit agenda items before meetings; } \\
\text { - Obtain feedback on product ideas and designs; } \\
\text { - Communicate with colleagues outside formal gatherings; } \\
\text { - Foster stronger communities in the workplace, minimising barriers and silos; and } \\
\text { - Reduce the need for presence on site. }\end{array}$ \\
\hline $\begin{array}{l}\text { Internet Surveys } \\
\text { and Polls }\end{array}$ & $\begin{array}{l}\text { - Obtain qualitative feedback in a structured and controlled format; } \\
\text { - Record documented opinions on project progress; } \\
\text { - Gather and analyse quantitative data; } \\
\text { - Determine customer interest in and opinions of new product and service ideas; } \\
\text { - Encourage anonymous input, which may otherwise may not have been made available; } \\
\text { - Measure employee morale during PD projects; and } \\
\text { - Gather market intelligence, including trends, data and public perceptions. }\end{array}$ \\
\hline Micro-Blogging & $\begin{array}{l}\text { - Inform others of what you are doing and encourage comments, questions and sharing via re-posts; } \\
\text { - Communicate and give feedback quickly to colleagues by posting short personalised messages to their news feeds; } \\
\text { - Inform team members of your current schedule and availability; } \\
\text { - Direct colleagues to informative content on the intranet or internet by re-posting; } \\
\text { - Provide status updates on product tasks and failures; } \\
\text { - Communicate with potential customers and suppliers; } \\
\text { - Provide a 'live support' for PD team members; and } \\
\text { - Gauge customer feedback and build product awareness. }\end{array}$ \\
\hline $\begin{array}{c}\text { Social Networking } \\
\text { Sites }\end{array}$ & $\begin{array}{l}\text { - Facilitate informal communication and collaboration within defined groups and teams; } \\
\text { - Create an open interactive working culture with reduced management barriers; } \\
\text { - Recognise and reward good work by adding "likes" and "personal comments" on individuals" profiles, which are visible } \\
\text { to colleagues and peers; } \\
\text { - Share information and content easily with colleagues; and } \\
\text { - Mentor individual groups and teams through the posting of constructive advice. }\end{array}$ \\
\hline RSS Feeds & $\begin{array}{l}\text { - Monitor news and information from multiple sources, including employee blogs, corporate headlines etc.; } \\
\text { - Keep abreast of employees' social networking posts and comments through one channel; } \\
\text { - Control the amount and flow of information to your computer; and } \\
\text { - Monitor social media activity streams to be aware of employee views. }\end{array}$ \\
\hline Slide Hosting & $\begin{array}{l}\text { - Share presentations with colleagues and dispersed teams; } \\
\text { - Store and access presentations when away from office; } \\
\text { - Display presentations when hosting online meetings; } \\
\text { - Embed presentations in blogs and other Web } 2.0 \text { services; and } \\
\text { - Locate presentations uploaded to other sites by colleagues. }\end{array}$ \\
\hline Video Calling & $\begin{array}{l}\text { - Conduct face-to-face discussions in real-time; } \\
\text { - Minimise cost of voice communication within dispersed teams; } \\
\text { - Deliver training and tutorials to non-co-located colleagues; } \\
\text { - Hold discussions with contemporaneous access to other means of information transfer; and } \\
\text { - Receive voice mail messages to your e-mail when unavailable. }\end{array}$ \\
\hline
\end{tabular}

\section{CONCLUSIONS}

The validation study demonstrated clearly that the groupware offers the capability of delivering an effective collaborative and knowledge sharing environment with additional communication channels on offer to end users. It confirmed that the groupware is usable and accessible to an acceptable standard, although it is evident that a larger sample size and more extensive trialing for a longer period would be beneficial. Indeed, one of the Team Members commented "I think it's a good service; it would have been more useful to my group if we had started the project using the groupware - we were introduced to the service once we had already got used to using e-mail for project group communication".

The study confirmed that the specific functionalities offered by the groupware were generally useful and easy to use. Both Managers and Team Members recognised that it could play a key role in document sharing, although the 
role of email and telephone as the primary communication channels would need to be addressed through the further development of the groupware into an in-depth PD collaboration package with comprehensive interoperability meeting current standards. The most positive outcome of the validation study was that clear evidence was provided that the delivered solution could facilitate collaborative and knowledge sharing processes, with users uploading and sharing their own content and ideas for comment and discussion by others; this may be seen as the essence of the challenge when making use of Web 2.0 tools for collaborative purposes.

It is planned in the near future that the proposed guidelines are successfully validated within a real-world PD environment within the collaborating company before being embedded into corporate processes for improving employee collaboration and knowledge sharing.

In conclusion, the study confirmed that Web 2.0-based groupware offers the potential to deliver a more effective collaborative and knowledge sharing environment with additional communication channels available. With regard to further work, a larger scale real world study is proposed to further validate the conclusions drawn in this paper.

\section{ACKNOWLEDGMENT}

This paper is based on work funded by the EPSRC under Grant No. EP/H501258/1 and BAE Systems' Electronic Systems Sector in Rochester, Kent, UK. The authors would like to thank all at BAE Systems Group and Tonbridge School, Kent, for their support with this project and their input to the Case Study.

Any opinions, findings and conclusions expressed in this paper are those of the authors and do not necessarily reflect those of BAE Systems Electronic Systems Sector, BAE Systems Inc. or BAE Systems PIc., the parent organisation.

\section{REFERENCES}

[1] J. Harrington and J. Blagden, "The neglected asset: information management in the UK aerospace industry", Business Information Review, Vol. 16, No. 3, pp. 128-136, 1999. http://dx.doi.org/10.1177/0266382994237243

[2] T. Captain, "Global Aerospace and Defence Industry Outlook: Expect another record year for commercial aerospace and continued declines in defence", 2014. [online]. Available at: http://www.icast.org.in/focus/AeroDefn14.pdf.

[3] M. Richardson, A. Danford, P. Stewart and V. Pulignano, "Employee Participation and Involvement: Experiences of Aerospace and Automobile Workers in the UK and Italy". European Journal of Industrial Relations, Vol. 16, No. 1, pp. 2137, 2010. http://dx.doi.org/10.1177/0959680109355309

[4] ADS, "Aerospace", 2014. [online]. Available at: https://www.adsgroup.org.uk/pages/62968081.asp.

[5] ECORYS, "FWC Sector Competitiveness Studies Competitiveness of the EU Aerospace Industry with focus on: Aeronautics Industry", 2009. [online]. Available at: http://ec.europa.eu/enterprise/sectors/aerospace/files/aerospace_st udies/aerospace study en.pdf.

[6] S. Johnstone, A. Dainty, and A. Wilkinson, "Integrating Products and Services Through Life: An Aerospace Experience", International Journal of Operations \& Production Management, Vol. 29, No. 5, pp. 520-538, 2009. http://dx.doi.org/10.1108/ 01443570910953612

[7] A.P. McAfee, "Enterprise 2.0: The Dawn of Emergent Collaboration", MIT Sloan: Management Review, Vol. 47, No. 7, pp. 1-10, 2006.
[8] I. Lee. Trends in E-Business, E-Services, and E-Commerce: Impact of Technology on Goods, Services, and Business Transactions. Western Illinois University, USA: IGI Global, 2013.

[9] S. Yardi, S.A. Golder and M.J. Brzozowski, "Blogging at Work and The Corporate Attention Economy", SIGCHI Conference on Human Factors in Computing. Boston, USA: 4 - 9 April 2009, pp. 2071-2080. http://dx.doi.org/10.1145/1518701.1519016

[10] J. Leino, E. Tanhua-Piiroinen and J. Sommers-Piiroinen, "Learning with Social Technologies: Workplace Learner Experiences of Wiki and Blog and Perceptions of PLE". IFIP Advances in Information and Communication Technology, Vol. 395, pp. 59-68, 2013. http://dx.doi.org/10.1007/978-3-642-37285$\underline{87}$

[11] P.H. Gray, S. Parise and B. Iyer, "Innovation Impacts of Using Social Bookmarking Systems". MIS Quarterly, Vol. 35, No. 3, pp. 629-643, 2011.

[12] Z. Zhao and W. Yu, "Enterprises' Micro-blogging Interaction: Based on Chinese Electric Household Industry", International Conference on Management Science and Engineering Management Lecture Notes in Electrical Engineering. Lisbon, Portugal: $25 \quad-30$ July 2014. pp. 135-144. http://dx.doi.org/10.1007/978-3-642-40078-0 11

[13] N. Novielli and S. Marczak, "Social Network Analysis for Global Software Engineering: Exploring Developer Relationships from a Fine-Grained Perspective", IEEE 8th International Conference on Global Software Engineering Workshops. Bari, Italy: 26 - 26 August 2013. pp. 47-48. http://dx.doi.org/10.1109/icgsew.2013.14

[14] H. Wu and H. Hsu, "A Framework of Generating Collaborative and Dynamic New Product Development Process". Asia University, pp. 220-224, 2008.

[15] D. Dutta and F. Ameri, "Product lifecycle management: closing the knowledge loops", Journal of Computer-Aided Design \& Applications, Vol. 2, No. 5, pp. 577-590, 2005. http://dx.doi.org/10.1080/16864360.2005.10738322

[16] C. Rebolledo and J. Nollet, "Learning from suppliers in the aerospace industry" International Journal on Production Economics, Vol. 129, No. 2, pp. 328-337, 2011. http://dx.doi.org/10.1016/j.ijpe.2010.11.008

[17] A. Ardichvili, M. Maurer, W. Li, T. Wentling and R. Stuedemann, "Cultural influences on knowledge sharing through online communities of practice", Journal of Knowledge Management. Vol. 10, No. 1, pp. 94-107, 2006. http://dx.doi.org/10.1108/ 13673270610650139

[18] E. Thomas, "Supplier Integration in New Product Development: Computer Mediated Communication, Knowledge Exchange and Buyer Performance". Journal of Industrial Marketing Management, Vol. 42, No. 6, pp. 890-899, 2013. http://dx.doi.org/10.1016/j.indmarman.2013.05.018

[19] V.M.R. Penichet, M.D. Lozano, J.A. Gallud and R. Tesoriero, "User interface analysis for groupware applications in the TOUCHE process model", Advances in Engineering Software, Vol. 40, pp. 1212-1222, 2009. http://dx.doi.org/10.1016/j.adveng soft.2009.01.026

[20] R. Duque, M.L. Rodríguez, M.V. Hurtado, C. Bravo and C. Rodríguez-Domínguez, "Integration of collaboration and interaction analysis mechanisms in a concern-based architecture for groupware systems", Science of Computer Programming, Vol. 77, No. 1, pp. 29-45, 2012. http://dx.doi.org/10.1016/j.scico. 2010.05.003

[21] S. Paroutis and A. Al Saleh, "Determinants of knowledge sharing using Web 2.0 technologies", Journal of Knowledge Management, Vol. 13, No. 4, pp. 52-63, 2009. http://dx.doi.org/10.1108/1367 3270910971824

[22] S. Panke and B. Gaiser, "With My Head Up in the Clouds": Using Social Tagging to Organize Knowledge", Business and Technical Communication, Vol. 23, No. 3, pp. 318-349, 2009. http://dx.doi.org/10.1177/1050651909333275

[23] BAE Systems plc, "Preliminary Annoucement and Presentation 2013", 2013. [online]. Available at: http://bae-systems-investorrelations-v2.production.investis.com/ /media/Files/B/BAESystems-Investor-Relations-V2/PDFs/results-andreports/results/2013/preliminary-results-2013-statement.pdf. 
[24] N. Milton, "Assessment of the current approach to Knowledge Management and Best Practice exchange". BAE Systems UK RoW Engineering Council, 2008.

[25] R.D. Evans, J.X. Gao, N. Martin and C. Simmonds, "An Investigation into the Potential Use of Social Media Technologies to Improve the Product Development Functions within the Aerospace and Defence Industry", International Conference on Manufacturing Research. Aston Business School, Birmingham, UK: 11 - 13 September 2012, pp. 718-723.

[26] R.D. Evans, J.X. Gao, S. Woodhead, N. Martin and C. Simmonds, "An Investigation into Collaboration and Knowledge Managementduring Product Development in the Aerospace and Defence Industry", International Conference on Knowledge Management and Information Sharing. Barcelona, Spain: 4-7 October 2012, pp. 113-118.

[27] R.D. Evans, J.X. Gao, N. Martin and C. Simmonds, "Using Web 2.0-Based Groupware to facilitate Collaborative Design in Engineering Education Scheme Projects", International Conference on Interactive Collaborative Learning. Dubai, United Arab Emirates: 03-06 December 2014, pp. 397-402.

\section{AUTHORS}

R. D. Evans obtained his $\mathrm{PhD}$ from the University of Greenwich in 2013. He completed research into how Web 2.0 Technologies could improve Collaboration and Knowledge Sharing in dispersed Product Development teams; the research was funded via an EPSRC Case Award in conjunction with BAE Systems' Electronic Systems sector, Rochester, UK. He is currently a Research Fellow within the Centre for Innovative Product Development and Manufacturing (CiPDM) at the University of Greenwich, United Kingdom.

J. X. Gao obtained his $\mathrm{PhD}$ from the University of Manchester in 1989. He is a world-class academic with international reputation in manufacturing engineering, particularly in the application of ICT in the manufacturing industry. He has directed a large number of research projects sponsored by UK and European research councils and leading manufacturing companies in the manufacturing related sectors and published over 210 papers in international journals and conferences. He is currently Medway Chair of Manufacturing Engineering within the CiPDM at the University of Greenwich.

N. Martin joined BAE Systems, Electronic Systems at Rochester as Chief Technologist in December 2004, and in 2012 was appointed Innovation and Growth Leader, where he champions technology strategy, new business pursuits and new product development. He is the main point of contact with external R\&T providers, including universities, research organisations and technology companies and he manages the 'core technology' R\&D programme. He is a BAE Systems Engineering Fellow.

C. Simmonds works for BAE Systems, Electronic Systems at Rochester and has over 30 years' experience in the Aerospace and Defence Electronics Industry. He has worked in both design and manufacturing, across a number of blue chip electronics companies. As a trained Leansigma Black belt with excellent communication skills, he is able to solve problems and realise opportunities for products and processes, both in-house and with major suppliers, and implemented business transformations through the application of the SHINGO principles of Operational Excellence.

This work was supported in part by the EPSRC under Grant EP/H501258/1. Manuscript received 15 March 2015. Published as resubmitted by the authors 02 June 2015 . 